\title{
INFLUENCE OF ROASTING CONDITIONS ON VOLATILE FLAVOR OF ROASTED MALAYSIAN COCOA BEANS
}

\author{
NAZARUDDIN RAMLI ${ }^{1,3}$, OSMAN HASSAN ${ }^{1}$, MAMOT SAID $^{1}$, \\ WAHID SAMSUDIN ${ }^{1}$ and NOR AINI IDRIS ${ }^{2}$ \\ ${ }^{1}$ School of Chemical Sciences \& Food Technology \\ Faculty of Science \& Technology \\ Universiti Kebangsaan Malaysia \\ 43600 Bangi, Selangor, Malaysia \\ ${ }^{2}$ Malaysian Palm Oil Board \\ 43650 Bangi, Selangor, Malaysia
}

Accepted for Publication December 16, 2005

\begin{abstract}
In this study, commercial Malaysian cocoa beans (SMC1A) were roasted in a forced airflow-drying oven for 20,30, 40 and $50 \mathrm{~min}$ at 120, 130, 140, 150, 160 and 170C. The products were evaluated for flavor compounds and sensory evaluation (as dark chocolate). The volatile fraction was isolated using the combined steam distillation-extraction procedure and was identified by gas chromatography-mass spectrometry. A quantitative descriptive analysis was used to evaluate the flavor intensity of the chocolates using a 9-point rating scale for selected flavor attributes, namely astringency, bitter taste, sour taste, cocoa and burnt. Panelists were asked to smell and taste the sample against a standard chocolate. It was found that there were significant differences in flavor compounds between the different conditions of roasting. The main flavoring compounds identified composed of aliphatic and alicyclic groups such as alcohol and ester, and heterocyclic groups such as pyrazine and aldehyde. A total of 19 volatile major components were identified: nine pyrazines (2,5-dimethyl-, 2,3-dimethyl-, 2-ethyl-6-methyl-, trimethyl-, 3-ethyl-2,5-dimethyl-, tetramethyl-, 2-ethenyl-6-methyl- and 3,5-dimethyl-2methylpyrazine); five aldehydes (5-methyl-2-phenyl-2-hexenal, benzaldehyde, benzalacetaldehyde and $\alpha$-ethyliden-benzenacetaldehyde); one methyl ketone (2-nonanone); two alcohols (linalool and 2-heptanol); and two esters (4-ethylphenyl acetate and 2-phenylethyl acetate). Based on the flavor profile of the compounds identified, an optimum production of the major flavoring compounds such as pyrazine, aldehyde, ketone, alcohol and ester occurred at

${ }^{3}$ Corresponding author. TEL: +603-8921-3817; FAX: +603-8921-3232; EMAIL: naza@ukm.my


$160 C$ for 30 min of roasting. Trimethylpyrazine and tetramethylpyrazine compounds together with 5-methyl-2-phenyl-2-hexanal were found to be good indicators for the evaluation of the roasting process. However, based on chocolate evaluation, the best roasting temperature was $150 \mathrm{C}$ for $30 \mathrm{~min}$, which gave the lowest astringency and at the same time gave the lowest bitter taste and low level of sour and burnt tastes. At 150C roasting temperature, the desirable cocoa flavor was at its optimum. Correlation coefficients among certain volatile flavor and sensory characteristics of cocoa beans and dark chocolate were significant $(\mathrm{P}<0.05)$.

\section{INTRODUCTION}

The cocoa bean quality preferred by cocoa and chocolate factories can be classified under four main criteria: flavor, cocoa butter hardness, purity and yield (Cook and Meursing 1982). The highest score given by the manufacturers is on the flavor aspect (Dimick and Hoskin 1981). Cocoa flavor developed under two fundamentally important stages during the processing of cocoa beans, namely fermentation and roasting. Cocoa beans used in the manufacture of chocolate have to undergo roasting process by means of dry heat treatment for the development of chocolate flavor. Flavor precursors developed during fermentation interact in the roasting process to produce the desired chocolate flavor. Roasting is the most important technological operation in the processing of cocoa beans. It brings about the formation of a characteristic brown color, mild aroma and texture of roasted beans. Convective roasting is the most commonly used method of thermal processing of raw cocoa beans, which are exposed to temperatures of 130-150C for 15-45 min (Nebesny and Rutkowski 1998). Properties of roasted beans, such as concentration of volatile flavor compounds, total acidity and fat content, depend on roasting conditions, mainly temperature and time of the process. Other parameters of thermal processing of cocoa beans, such as humidity and flow rate of air, also seem to affect the quality of the final product.

The flavor produced is a result of combinations of 400-500 compounds (Dimick 1983) including pyrazines, aldehydes, ethers, thiazoles, phenols, ketones, alcohols, furans and esters (Dimick and Hoskin 1981). Aldehydes and pyrazines are among the major compounds formed during roasting. They are formed through the Maillard reaction and Strecker degradation of amino acids and sugars during roasting (Heinzler and Eichner 1992). According to Keeney (1972), the roasting process not only to generates new volatile compounds for specific flavour through pyrolysis of sugars, but also loss of minor compounds that affect on the final flavour of chocolate. The degree of chemical changes depends on the temperature applied during the process. During the roasting 
process, the flavor precursors present in the fermented cocoa beans are partially changed or removed. Certain aroma substances, such as carbonic acids, aldehydes, ketones, esters and essential oils, are very volatile, while other substances, such as polyphenoloxidases, purines and melanoidins, are not volatile (Nazaruddin et al. 2000)

In general, the choice of roasting conditions depends upon the type of beans, period of harvesting, their origin, postharvest treatment and type of flavor desired. The effective temperature for the development of cocoa flavor also depends on the origin of the beans (Dimick 1983). Some beans, such as Maracaibos, Caracas and Criollo, may require shorter heat treatment at 131141C (Cook and Meursing 1982), whereas some other beans such as Accra and Bahia require higher heat treatment ranging from 146-184C (Dimick and Hoskin 1981).

According to Ö Zdemir and Devres (2000), temperature is the main factor affecting coloration of roasted cocoa beans. Lee et al. (2001) reported that the dynamics of pigment formation upon roasting depended on gradient of temperature. The concentration of brown pigments peaked at $134 \mathrm{C}$ and gradually decreased when the temperature of thermal processing continued to rise. Ziegleder (1982) divided the roasting parameters for the development of cocoa flavor into four zones, namely slight (100-120C), normal (120140C), strong (140-160C) and over-roasted (>160C) conditions. The optimum roasting time practised in the industry depends mainly on heat transfer and the temperature gradient in the bean. If the maximum temperature and time are exceeded, signs of over-roasting become noticeable, which decrease the quality of the products (Heinzler and Eichner 1992). Currently, no systematic study was done on the flavor formation of standard Malaysian cocoa bean (SMC1A) during roasting.

The aim of this study was to determine how the variation in cocoa roasting conditions influences cocoa flavor as assessed by a sensory panel. In determining the total product quality, mechanical or chemical test must be accompanied by a sensory test because no instrument can measure human perception. In addition, the studies were conducted to evaluate the effect of various conditions of roasting on sensory characteristics of dark chocolate.

\section{MATERIALS AND METHODS}

\section{Materials}

The Malaysian cocoa beans (grade SMC1A) were obtained from KL-Kepong Cocoa Specialities Sdn. Bhd., Klang, Selangor, Malaysia. $\mathrm{SMC1A}$ is a premium-grade produce in Malaysia, which contains bean count 
$\leq 100$ (per $100 \mathrm{~g}$ ), $\leq 3 \%$ moldy, $\leq 2.5$ insect damaged and $<3 \%$ slaty beans. The cocoa beans were stored in an air-conditioned room (22-23C) until used. All the flavor compound standards such as pyrazine, aldehyde, ketone, etc. (purity: 99-100\%) were purchased from Sigma Chemical Company (St. Louis, MO). Milli-Q (Millipore, Bedford, MA) double distilled water (resistance = $18 \mathrm{Mx}$ ) was used. All solvents and reagents were of American Chemical Society grade or better.

\section{Roasting and Sample Preparation}

Approximately 500-g portions of cocoa beans of uniform size were poured and roasted in a forced airflow-drying oven (Memmert, Schwabach, Germany). The parameters of thermal processing were as follows: temperatures of 120,130,140,150, 160 and 170C for 20, 30, 40 and 50 min; airflow rate of $1.0 \mathrm{~m} / \mathrm{s}$, which was regarded as the optimum flow rate based on the results of earlier studies carried out by Krysiak et al. (2003); and relative air humidity of $0.5 \%$ at all the temperatures. The presented parameters of thermal processing of cocoa beans refer to the air, which was in direct contact with roasted beans. The roasting process was conducted without air circulation. The roasting of cocoa beans was terminated when the water content of the roasted materials was $\pm 5 \%$ (optimal in terms of their grinding and fat extraction). All extraction steps were done with protection against daylight, in duplicate. Next, the roasted cocoa beans were cooled to approximately room temperature, deshelled and ground using a laboratory minibreaker and winnower (John Gordon \& Co, Lancashire, UK) into 60-mesh powder size and stored in a sealed vacuum plastic bag prior to use. The precision of measurements of temperature, airflow rate and its humidity was $\pm 1 \mathrm{C}, \pm 0.05 \mathrm{~m} / \mathrm{s}$ and $\pm 0.5 \%$, respectively. To determine the effects of the applied roasting conditions on the dynamics of changes in the flavor of the beans, the whole portions of roasted cocoa were taken off the chamber after determined time limits (10-50 min).

\section{Flavor Extraction}

Ground roasted cocoa $(150 \mathrm{~g})$ was placed into 2-L round-bottom flask containing $1 \mathrm{~L}$ of boiling deionized water $(\mathrm{pH}$ 5.6) and connected to combined steam distillation and extraction apparatus. The mixture was heated to boiling in a heating mantle (Electromantle, Stafford, UK). The extraction was allowed to proceed for $1 \mathrm{~h}$ using $30-\mathrm{mL} n$-pentane as the extraction solvent. The extract was neutralized with an aqueous solution of sodium carbonate, dried with anhydrous sodium sulfate and then gently concentrated by Vigreux-column (PLT Puchong, Malaysia) distillation to $1 \mathrm{~mL}$ by heating at 40C in a water bath. The concentrated extract was then transferred into glass ampules, sealed and stored at cold room temperature (5C). 


\section{Identification of the Volatile Flavor Compounds}

The volatile components in the extracts were analyzed using a HewlettPackard 6890 gas chromatograph equipped with a mass selective detector (HP 6890 GC/MSD, Hewlett-Packard, San Fernando, CA) and Wiley Library. The gas chromatography (GC) conditions were as follows: detector temperature set at 280C; injector 200C; column (HP-INNOwax-cross-linked polyethylene glycol, $30 \mathrm{~m} \times 0.32 \mathrm{~mm}$ i.d., $0.25 \mu \mathrm{m}$, HP-INNOwax, Agilent Technologies, Palo Alto, CA) set at conditions of temperature programming as follows: $50 \mathrm{C}$ for $5 \mathrm{~min}$ and then the temperature was increased to $200 \mathrm{C}$ for $5 \mathrm{~min}$ at $4 \mathrm{C} / \mathrm{min}$. The temperature was then kept constant at $200 \mathrm{C}$ for $5 \mathrm{~min}$. The sample $(1 \mu \mathrm{L})$ was injected into the GC using helium as carrier gas at a flow rate of $1.3 \mathrm{~mL} /$ min. Injections were conducted with a split ratio of 1:20. Fragmentation was performed by Electrothermal Impact, with ionization voltage at $70 \mathrm{eV}$ and scan mode between 50 and 450 mass units. The mass spectra obtained for all compounds were compared with the mass spectra obtained from the equipment database and standard compounds. Quantification was carried out from peak areas of components (Table 1).

\section{Chocolate Preparation}

Dark chocolates were prepared by the standard method (Cook and Meursing 1982). After roasting, about 500-g cocoa nibs was ground with an end runner mill for about $1 \mathrm{~h}$ to produce cocoa liquor. Dark chocolates were prepared using the following recipe: sugar $(46 \%)$, cocoa liquor $(19 \%)$, lecithin $(0.41 \%)$ and cocoa butter $(0.02 \%)$. The dark chocolates were kept in a capped sample bottle and kept in an oven maintained at 45-50C.

\section{Sensory Assessment of the Chocolates}

An analytical sensory test was designed to determine the flavor of the chocolates. The sensory test was conducted in an air-conditioned sensory laboratory equipped with individual panel booths. The lighting system consisted of fluorescent red and blue lights. The red light was used to mask any color difference among the samples. There were 12 panelists that were selected based on their ability to discriminate small differences among the samples. Sixty samples were prepared and tested. These samples were divided into sets of three. The chocolate samples were cut into equal sizes and served on white plates. Three-digit random numbers were used to code each sample. At one setting (each day), each panel evaluated three samples served together with a standard (reference) chocolate. A quantitative descriptive analysis was used to evaluate the flavor intensity of the chocolates using a 9-point rating scale. The flavor attributes included astringency, bitter taste, sour taste, cocoa 
TABLE 1.

$M / Z$ COMPARISON BETWEEN COCOA BEANS AND STANDARD OF FLAVOR COMPOUNDS IDENTIFIED BY GAS CHROMATOGRAPHY-MASS SELECTIVE DETECTOR (WILEY LIBRARY)

\begin{tabular}{|c|c|c|c|}
\hline Compound & $\begin{array}{l}\text { Molecular } \\
\text { weight }\end{array}$ & $\begin{array}{l}\text { Retention } \\
\text { time } \\
(\mathrm{min})\end{array}$ & $m / z$ (Relative) \\
\hline 2,5-Dimethyl- & 108 & 10.311 & $\begin{array}{l}42(77656), 38(7656), 81(7184), 108(55112), \\
\quad 52(4357), 64(1237), 67(1118)\end{array}$ \\
\hline 2,3-Dimethyl- & 122 & 11.901 & $\begin{array}{l}121(7032), 56(1030), 94(1014), 42(778), \\
\quad 66(694)\end{array}$ \\
\hline 2-Ethyl-6-methyl- & 122 & 12.174 & $\begin{array}{l}121(88568), 94(13365), 56(13045), 42(9930), \\
\quad 66(8090), 80(1679)\end{array}$ \\
\hline Trimethyl- & 122 & 12.406 & $\begin{array}{l}\text { 122(144000), 81(26856), 27(23928), } \\
\quad 42(217472), 54(19384), 38(10615), \\
\quad 66.05(3258), 107(2940)\end{array}$ \\
\hline $\begin{array}{l}\text { 3-Ethyl-2,5- } \\
\text { dimethyl- }\end{array}$ & 136 & 13.812 & $\begin{array}{l}\text { 135(139264), 42(80192), 39(52800), } \\
\text { 56(35736), 108(25504), 53(16160), } \\
\text { 121(9033), 80(7613), 66(6251) }\end{array}$ \\
\hline $\begin{array}{l}\text { 2-Ethyl-3,5- } \\
\text { dimethyl- }\end{array}$ & 136 & 13.944 & $\begin{array}{l}135(7411), 42(2355), 54(1483), 108(1036) \\
\quad 80(430), 121(284)\end{array}$ \\
\hline Tetramethyl- & 136 & 14.380 & $\begin{array}{l}\text { 54(682432), 136(582976), 42(447936), } \\
\text { 27(152064), 95(30096), 80(16464), } \\
\text { 121(13586), 50(3340) }\end{array}$ \\
\hline 2-Ethenyl-6-methyl- & 120 & 15.033 & $\begin{array}{c}120(30776), 52(26512), 39(11411), 94(5025), \\
27(3844), 66(2312), 79(1282), 105(810)\end{array}$ \\
\hline $\begin{array}{l}\text { 3,5-Diethyl-2- } \\
\text { methyl- }\end{array}$ & 150 & 14.859 & $\begin{array}{c}149.10(19750), 28(13458), 135.10(6047) \\
56(3825), 42(2687), 122.05(2472), \\
67.05(1652), 107.05(1395), 93.95(779)\end{array}$ \\
\hline $\begin{array}{l}\text { 5-Methyl-2-fenyl-2- } \\
\text { hexanal }\end{array}$ & 188 & 27.630 & $\begin{array}{l}117(55792), 104(40816), 188(29496) \\
91(27288), 145(18552), 132(14903) \\
173(12613)\end{array}$ \\
\hline Benzaldehyde & 124 & 22.571 & $39(523), 77(208), 105(184)$ \\
\hline Benzalacetaldehyde & 120 & 18.645 & $\begin{array}{l}91(215360), 65(45048), 120(37648) \\
51(13920), 37(2981), 61(2935)\end{array}$ \\
\hline $\begin{array}{l}\alpha \text {-Ethyliden- } \\
\text { benzenacetaldehyde }\end{array}$ & 146 & 24.809 & $\begin{array}{l}117(25992), 146(18984), 63(4189), 78(3821) \\
\quad 89(3808), 102(2425), 131(1539)\end{array}$ \\
\hline 2-Nonanone & 142 & 12.404 & $\begin{array}{l}58(226806), 43(209600), 71(43256), 85(7532), \\
\quad 124(5992),\end{array}$ \\
\hline Linalool & 86 & 16.571 & $\begin{array}{l}71(52408), 93(31816), 80(14478), 27(13490), \\
121(8718), 107(3197), 136(2635)\end{array}$ \\
\hline 2-Heptanol & 116 & 10.635 & $\begin{array}{l}45(1007872), 55(158272), 27(70752) \\
\text { 83(63760), 98(19936), 59(6744), }\end{array}$ \\
\hline 4-Ethylphenyl acetate & 164 & 22.160 & $\begin{array}{l}91(58528), 65(8203), 164(7170), 51(2275), \\
\quad 104(2118), 119(957), 30(581)\end{array}$ \\
\hline 2-Phenylethyl ester & 164 & 22.480 & $\begin{array}{l}104(252160), 43(197056), 91(46992) \\
\quad 65(19712), 77(15486), 51(15023), 121(803)\end{array}$ \\
\hline
\end{tabular}


and burnt. The panelists were asked to smell and taste the samples against the standard chocolate.

\section{Statistical Analysis}

The statistical significance was determined using analysis of variance and Duncan's multiple range test using SAS (1989) version 6.04. Significant differences were considered when $P<0.05$. Values given as means \pm SD are presented in the text and tables.

\section{RESULTS AND DISCUSSION}

\section{Flavor Profile During Roasting}

The gas chromatogram of flavor profile recovered from roasted cocoa beans (150 for $30 \mathrm{~min}$ ) is presented in Fig. 1. Peaks 1 through 28 represent the flavor compounds isolated from the beans. Each compound identified in the compound fraction had been found previously in cocoa beans and its products by other investigators (Table 2 ).

Tables 3-6 show the volatile components produced by different roasting regimes and identified by GC-mass selective (MS) detector. There were 28 major compounds identified in this study including nine pyrazines (2,5-dimethyl-, 2,3-dimethyl-, 2-ethyl-6-methyl-, trimethyl-, 3-ethyl-2, 5-dimethyl-, tetramethyl-, 2-ethenyl-6-methyl- and 3,5-dimethyl-2methylpyrazine); five aldehydes (5-methyl-2-phenyl-2-hexenal, benzaldehyde, benzalacetaldehyde and $\alpha$-ethyliden-benzenacetaldehyde); one methyl ketone (2-nonanone); two alcohols (linalool and 2-heptanol); and two esters (4-ethylphenyl acetate and 2-phenylethyl acetate). The results showed that the concentrations of trimethyl- and tetramethylpyrazine were high for all the samples (more than $0.2-6 \mathrm{mg} / \mathrm{kg}$ from the total pyrazine in each sample). The presence of pyrazine compounds in roasted foodstuffs such as cocoa, coffee and peanut has been reported (Rohan and Stewart 1965). However, the concentrations of the other components were low. Besides pyrazines, esters and several organic acids such as acetate were also detected in roasted beans. It was found that the concentration of ethyl acetate increased during roasting.

The same pyrazines were present in all the samples but in different proportions. A major quantitative difference involved primarily the dimethyl, trimethyl and tetramethyl pyrazine peaks. The most abundant pyrazine identified was tetramethylpyrazine, which was present at an extremely high concentration in the roasted cocoa beans. Tetramethylpyrazine accounted for over $90 \%$ of the pyrazine content of the roasted cocoa beans. This phenomenon has been reported by Reineccius et al. (1972), who found that tetramethylpyrazine 


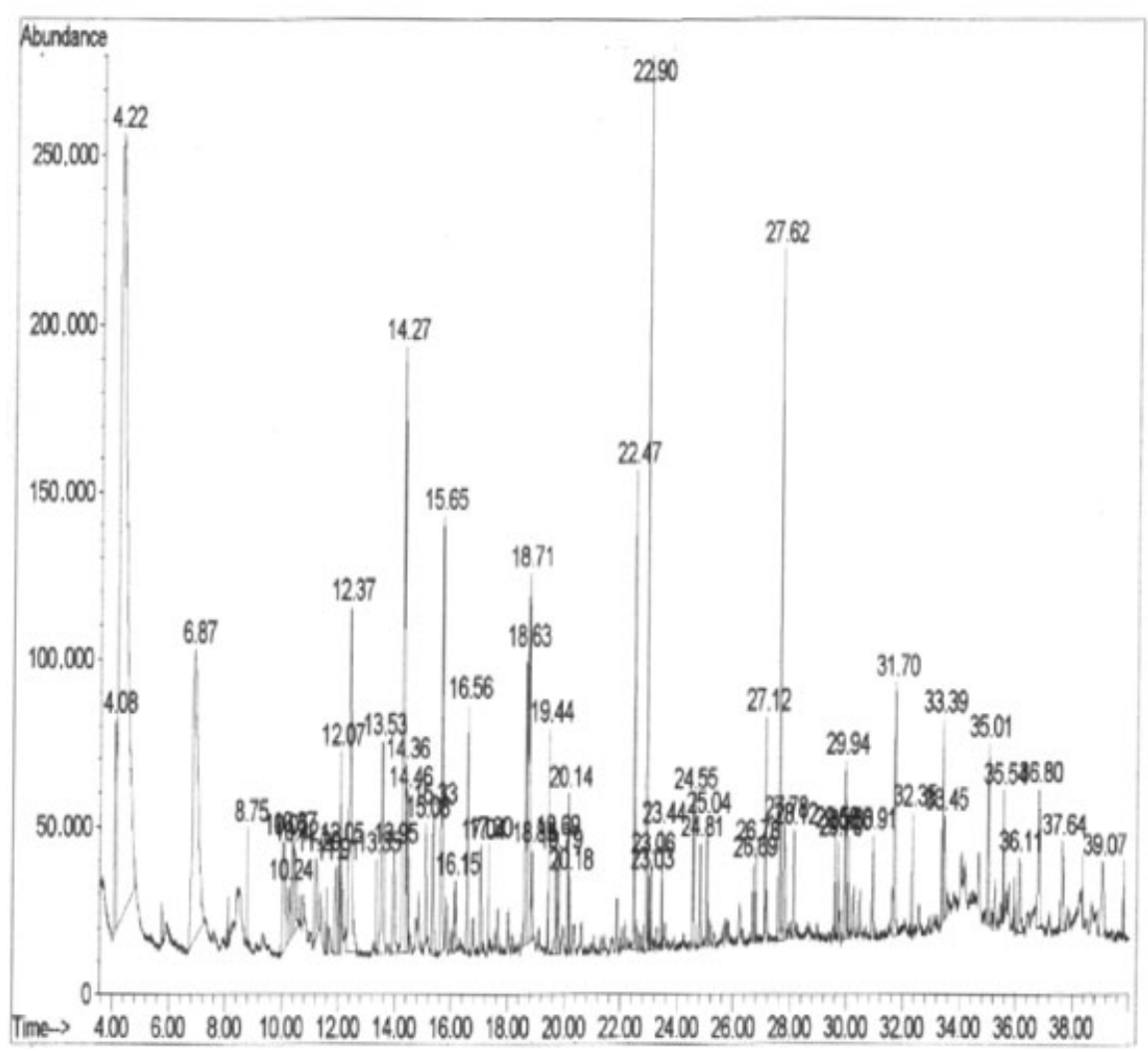

FIG. 1. CHROMATOGRAMS OF FLAVOR COMPOUNDS BY ROASTING OF MALAYSIAN COCOA BEANS AT 150C FOR 40 MIN USING STEAM DISTILLATION

The profile was obtained by gas chromatography-mass selective detector. Peak numbering refers to compounds listed in Table 1.

accounted for almost all the pyrazine content of cocoa beans roasted for $30 \mathrm{~min}$ at $70 \mathrm{C}$. Tetramethylpyrazine is known to be a metabolic product of Bacillus subtilis, and its presence is an indication of $B$. subtilis activity during the fermentation of cocoa beans (Gill et al. 1984). Tetramethylpyrazine is one of the important components of cocoa flavor that can be used as cocoa flavor enhancer (Rohan and Stewart 1965; Nebesny and Rutkowski 1998). From organoleptic descriptions, trimethyl- and tetramethylpyrazine possess a nutty, grassy and pungent persistent cocoa note (van Praag et al. 1968). Tetramethylpyrazine was found in fermented and unroasted cocoa beans (Renniciues et al. 1972). Besides thermal degradation, tetramethylpyrazine formed in cocoa beans through biosynthetic reactions (Ziegleder 1982). From 


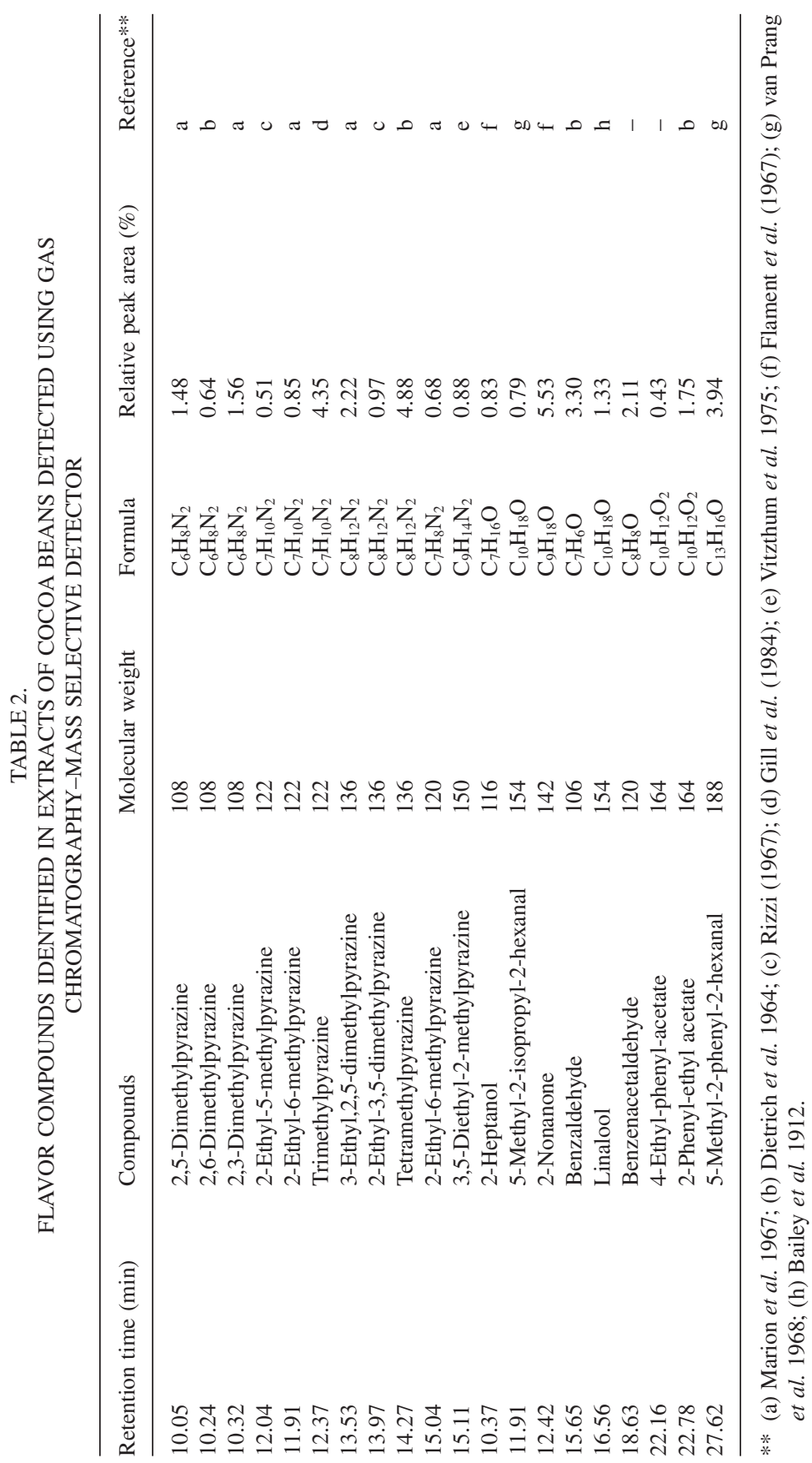




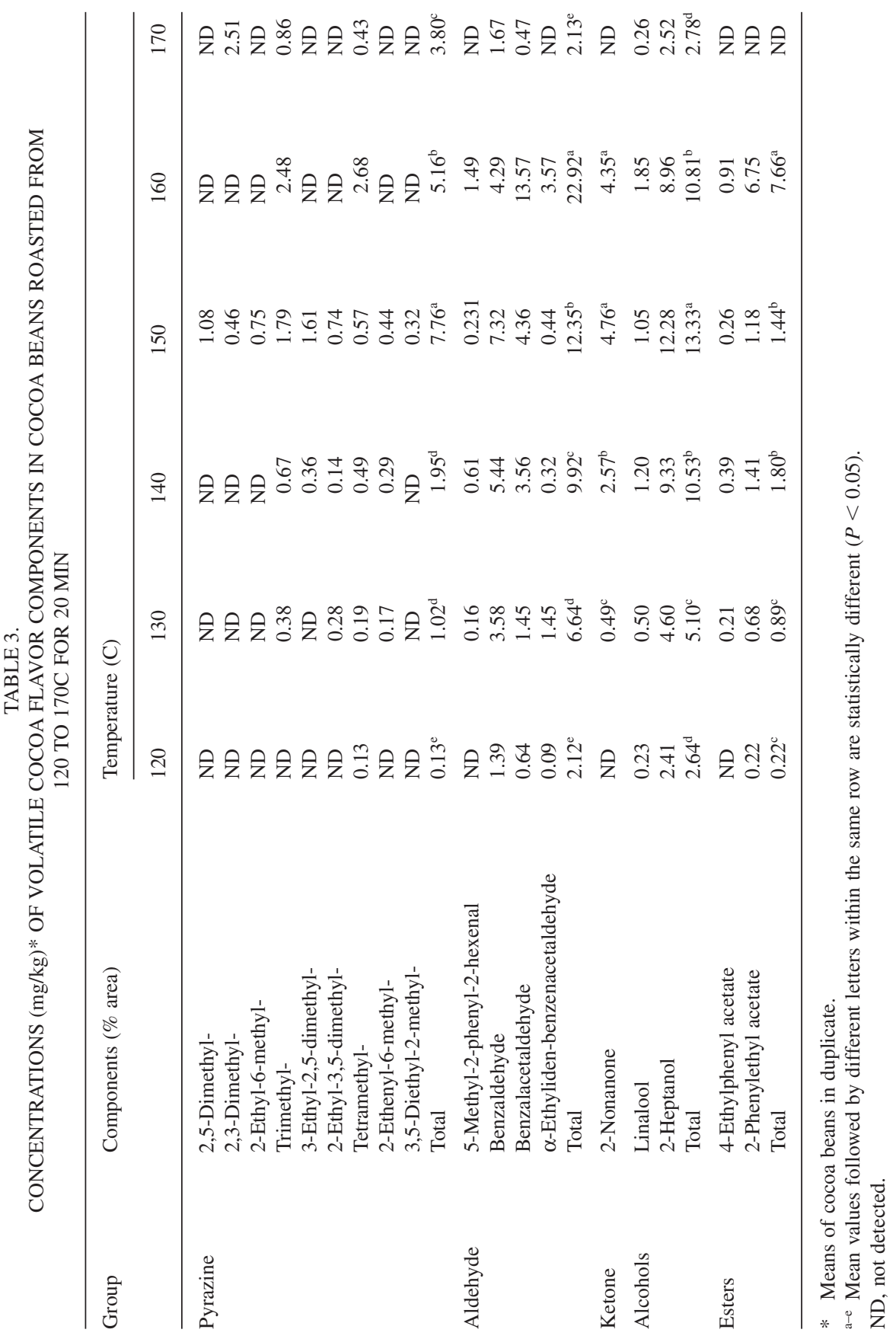




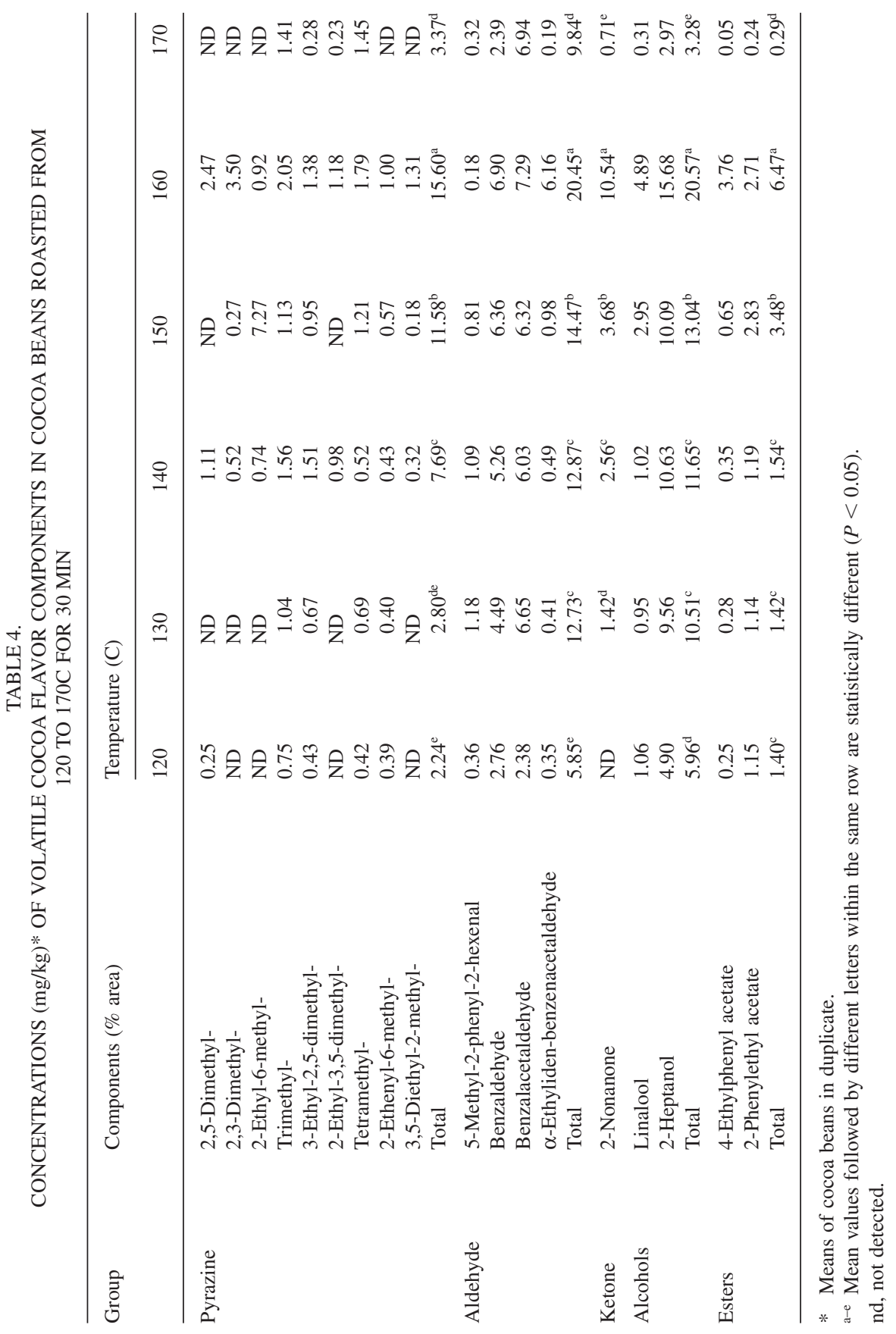




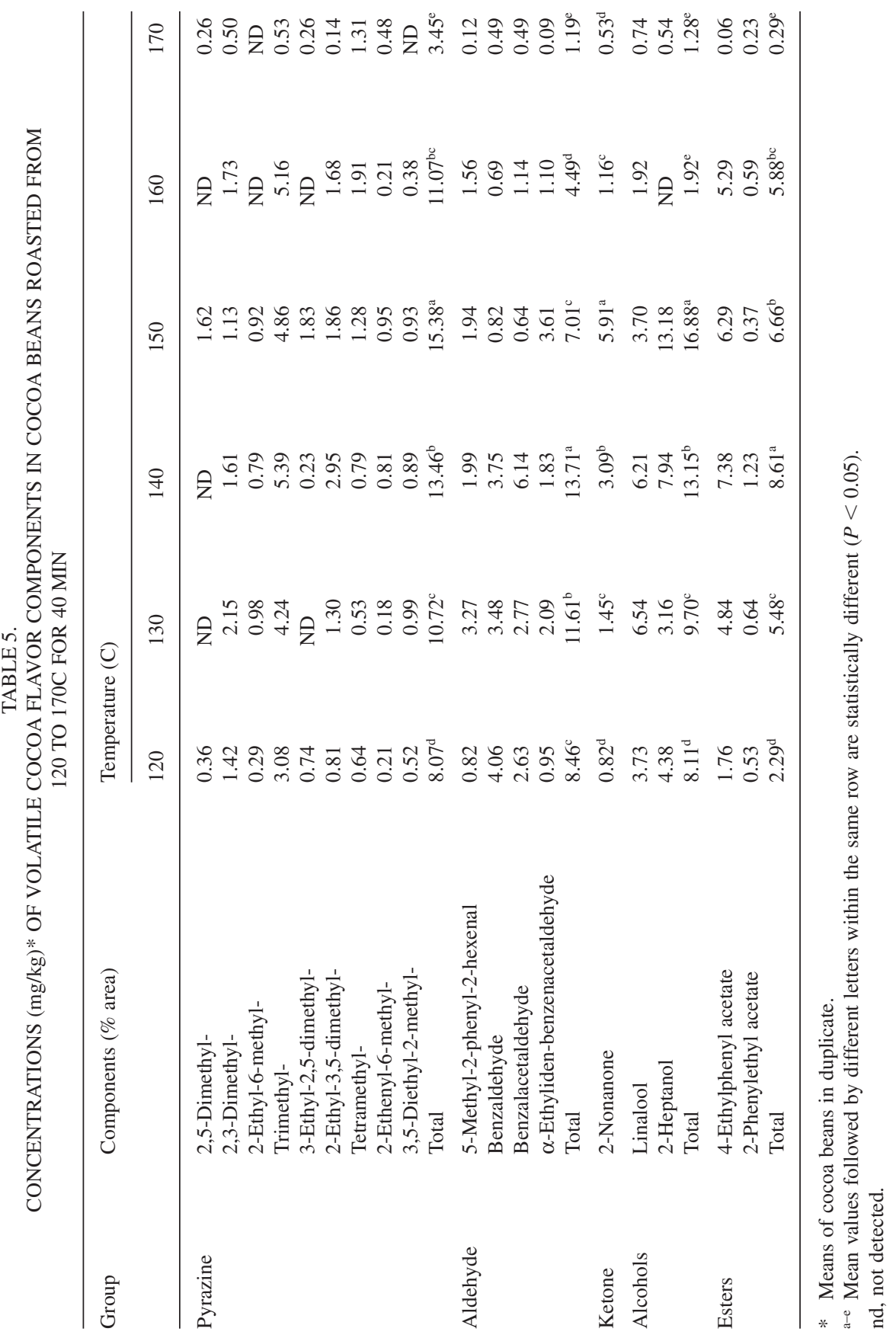




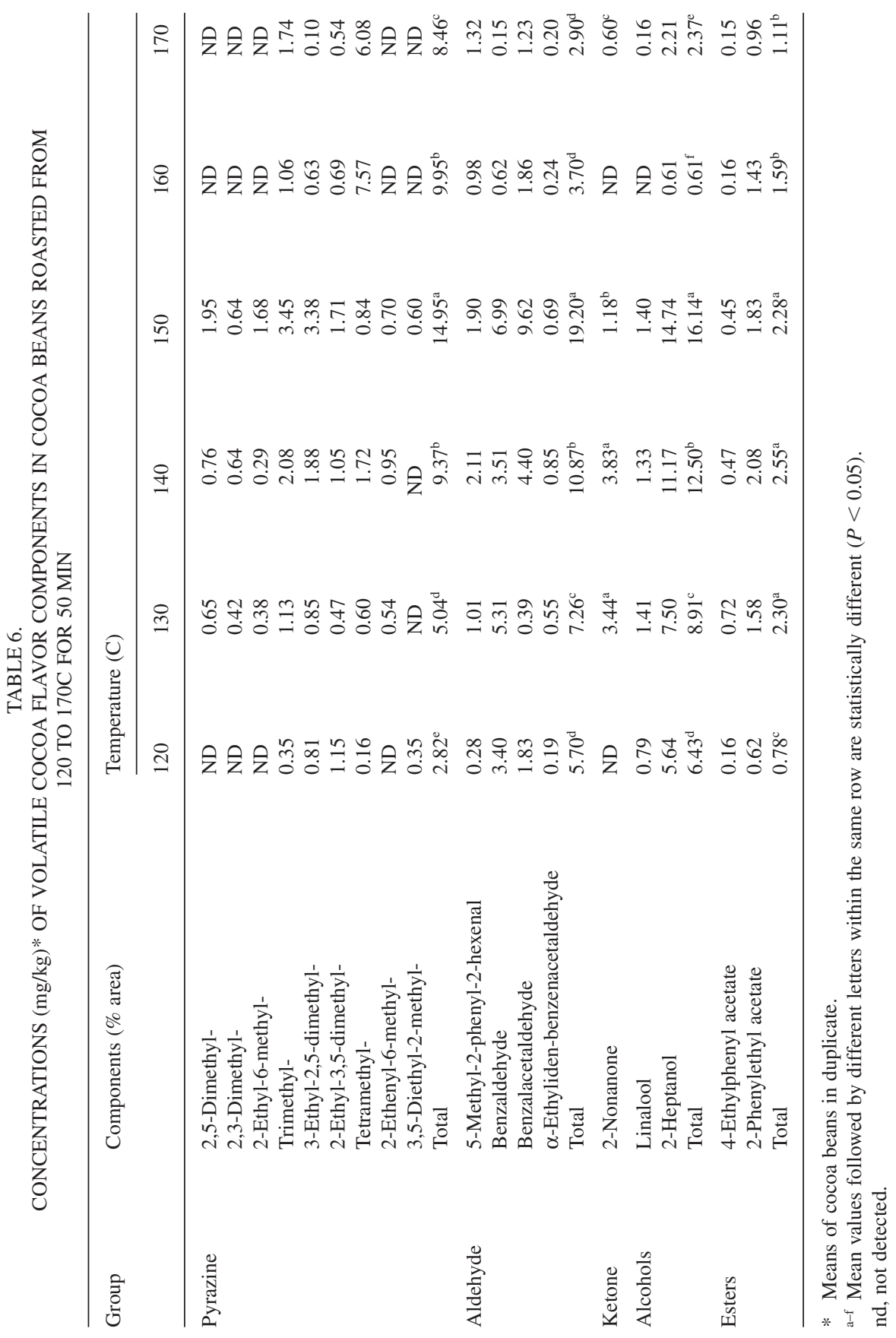


Tables 3-6, tetramethylpyrazine is the major pyrazine compound, and its concentration shows a linear correlation with roasting temperature, at optimum condition of roasting at $160 \mathrm{C}$ for $40 \mathrm{~min}$ ( $>7 \mathrm{mg} / \mathrm{kg}$ of tetramethylpyrazine).

Besides tetramethylpyrazine, trimethylpyrazine was also found in roasted cocoa beans. The compound was not found in unroasted beans. Hence, it can only be formed during the roasting process. This compound is an important component of roasted food flavor, including roasted cocoa flavor. Trimethylpyrazine can also be used as an indicator for the degree of cocoa roasting (Heinzler and Eichner 1992). The optimum condition of roasting was $140 \mathrm{C}$ for $40 \mathrm{~min}(5.4 \mathrm{mg} / \mathrm{kg})$. Besides tetramethylpyrazine and trimethylpyrazine, other methylpyrazines such as 3-ethyl-, 2,5-dimethyl-, 2-ethenyl-6-methyl-, 2,5dimethyl- and 2-ethyl-3,5-dimethyl- were also detected in cocoa beans but in low concentrations. This group of compounds can be detected after exceeding the time and temperature of roasting or as a sign of over-roasting (high temperature or long time of roasting).

From the quantitative analysis using GC-MS, four important aldehydes detected in all the samples are benzaldehyde, benzenacetaldehyde, $\alpha$-ethyl benzenacetaldehyde and 5-methyl-2-phenyl-2-hexenal. Aldehydes are common flavor components of natural products and are often used as food flavoring. Certain combinations of aldehydes with acyl-sulfur compounds are responsible for some of the important flavor notes of chocolate aroma (Dietrich et al. 1964). However, other aldehydes such as isovaleraldehyde and isobutyldehyde (Ziegleder 1982) were not detected, and this may be because of the lack of amino acid precursors or both conditions in the beans during the roasting process which might not be conclusive to the reaction (Memmert et al. 1982). The optimum conditions of roasting to generate the aldehyde compounds are $150-160 \mathrm{C}$ for $20-40 \mathrm{~min}$ (range between 17 and $22 \mathrm{mg} / \mathrm{kg}$ of total aldehydes). The presence of aldehydes can also be used as an indicator for the degree of roasting of cocoa. According to organoleptic evaluation results, 5-methyl-2-phenyl-2-hexenal possesses a deep bitter, persistent cocoa note (van Prang et al. 1968). Tables 4-6 show that besides the 5-methyl-2-phenyl2-hexenal compound, other aldehyde compounds such as benzaldehyde, benzenacetaldehyde, $\alpha$-ethyl benzenacetaldehyde contents are always high in all conditions of roasting. These results do not agree with those of Ziegleder (1982) who indicated that isovaleraldehyde and isobutyraldehyde contents increase with temperature.

Two alcohols found in cocoa beans during roasting are linalool and 2-heptanol. Linalool and 2-heptanol are also important to cocoa flavor, which can be used as cocoa flavoring materials. These compounds have been identified as volatile compounds of thermally degradable amino acids. These compounds have a strong green flavor and sweet aroma, which could contribute to the cocoa bean flavor. The data show changes of concentrations of linalool and 2-heptanol 
in relation to the degree of roasting of cocoa beans. It is interesting to note that at low temperature of roasting, the alcohol compounds were low, but increased steadily as a linear function of temperature while the last remained quite constant and decreased at over-roast conditions (150-160C for $50 \mathrm{~min}$ ).

Two esters, namely 4-ethylphenyl acetate and 2-phenylethyl acetate were detected in cocoa bean during roasting (Tables 3-6). Esters have a fragrance attribute and are common important flavor components of natural products. These compounds increased during roasting, especially when the temperature and time regime exceeded the optimum condition (over-roasting). However, Baigrie and Rumbelow (1987) claimed that 2-phenylethyl acetate is an important contributor to the fruity flavor attribute exhibited by Asian cocoa liquor. In this study, the data show that both esters were detected at all conditions of roasting, and the optimun conditions were $130-160 \mathrm{C}$ for $40 \mathrm{~min}$ at 5.4$8.6 \mathrm{mg} / \mathrm{kg}$, respectively.

\section{Sensory Evaluation of Dark Chocolate}

Figure 2 shows a PCA scatter plot of the cocoa liquor samples with respect to their sensory attributes. The panelists noted the beginning of the roasting treatment $(120 \mathrm{C}, 20 \mathrm{~min})$; there was a significant decrease in astringency $(P<0.05)$. The trend shows that the higher the temperature and the longer the time of roasting, the lower is the astringent taste. Polyphenol compounds, namely epicatechin, catechin and procyanidin are responsible for the astringent taste in cocoa (Kim and Keeney 1984; Nazaruddin et al. 2000). At high temperature and with longer roasting time, these compounds were degraded, thus decreasing the astringent taste. The best roasting condition for low astringency was $150 \mathrm{C} / 40 \mathrm{~min}$. Although roasting at $170 \mathrm{C}$ for $50 \mathrm{~min}$ gave the least astringency, it is uneconomical. Moreover, at this treatment condition, the cocoa would be very bitter because it got burnt.

There was a gradual decrease in bitter taste with the increase in roasting temperature from 120 to $140 \mathrm{C}$. The bitter taste remained low at $150 \mathrm{C}$. When temperature was increased to $160 \mathrm{C}$, there was a significant increase in the bitter taste, particularly when roasting time was increased to $50 \mathrm{~min}$. The bitter taste continued to increase at higher temperature of $170 \mathrm{C}$ and with increasing roasting time. Xanthine alkaloids, namely caffeine, and theobromine are responsible for the bitter taste of cocoa beans (Nazaruddin et al. 2001).

The cocoa flavor increased with increasing temperature and time of roasting. However, roasting at $120 \mathrm{C}$ for $50 \mathrm{~min}$ produced greater cocoa flavor than roasting at $130 \mathrm{C}$ for $10 \mathrm{~min}$. Roasting at $130 \mathrm{C}$ for $50 \mathrm{~min}$ resulted in higher cocoa flavor than roasting at $140 \mathrm{C}$ for $10 \mathrm{~min}$. The best roasting temperatures were 140 and $150 \mathrm{C}$. The optimum roasting condition that gave the perceived cocoa flavor was at $150 \mathrm{C}$ for $30 \mathrm{~min}$. Scores for cocoa flavor 

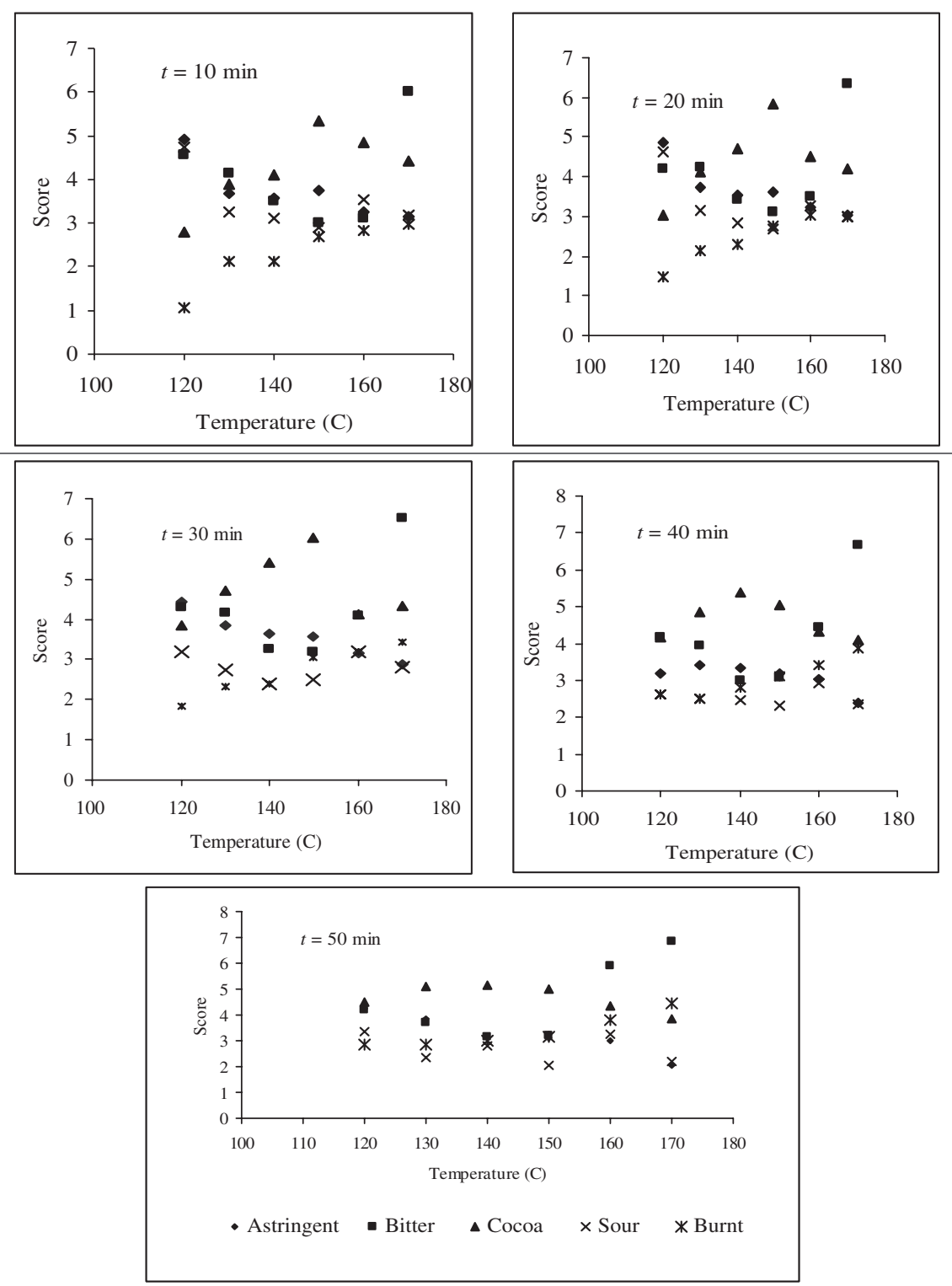

FIG. 2. SCATTER PLOT OF THE DARK CHOCOLATE WITH RESPECT TO ITS SENSORY ATTRIBUTES AT DIFFERENT ROASTING CONDITIONS 
decreased with further increase in temperature. It was most likely because at very high temperature, the cocoa bean became burnt, which attributed to the increase in burnt and bitter taste. The burnt and the bitter taste could have masked any increase in cocoa flavor. Sour taste is undesirable in chocolate. In general, there was a decrease in sour taste with increasing roasting time from 10 to $40 \mathrm{~min}$. However, for $50 \mathrm{~min}$ and at roasting temperatures of 120,140 and $160 \mathrm{C}$, there was an increase in sour taste, although such an increase was not noted at roasting temperatures of 130,150 and $170 \mathrm{C}$. The sour taste was lowest at the roasting temperature of $150 \mathrm{C}$ for $50 \mathrm{~min}$.

Time and temperature of roasting had a significant effect on burnt flavor. Burnt flavor was lowest at $120 \mathrm{C} / 10 \mathrm{~min}$ of roasting and significantly higher as the time of roasting was increased from 40 to $50 \mathrm{~min}$. It was noted that the burnt flavor was lower at 130, 140, 150 and $170 \mathrm{C}$ for 10 and $50 \mathrm{~min}$, respectively. Thus, the burnt taste increased with increasing time and temperature of roasting.

\section{CONCLUSIONS}

It has been shown that flavor profiling of Malaysian cocoa beans during roasting has major components of pyrazines such as 2,5-dimethyl-, 2,3dimethyl-, 2-ethyl-6-methyl-, trimethyl-, 3-ethyl-, 2,5-dimethyl-, tetramethyl-, 2-ethenyl-6-methyl- and 3,5-diethyl-2-methylpyrazine. Based on the quantity of trimethyl- and tetramethylpyrazine in all cocoa beans, the study shows that both compounds can be used as indicators of the roasting process, including benzaldehyde, 2-nonanone, linalool and 2-phenylethyl acetate for aldehydes, ketones, alcohols and esters, respectively. Taking the overall flavor into account, the best roasting temperature was at $150 \mathrm{C}$, which gave the lowest astringency and at the same time gave the lowest bitter taste and low level of sour and burnt tastes. At $150 \mathrm{C}$ roasting temperature, the desirable cocoa flavor was at its optimum. The recommended roasting time is $30-40 \mathrm{~min}$.

\section{ACKNOWLEDGMENT}

We are very grateful to the Malaysian National Scientific Council on Research \& Development, under the Intensification of Research in Priority Areas (IRPA 03-04-07-0307) program for the financial support of this project.

\section{REFERENCES}

BAIGRIE, B.D. and RUMBELOW, S.J. 1987. Investigation of flavour defects in Asian cocoa liquor. J. Sci. Food Agric. 39, 357-368. 
BAILEY, S.D., MITCHELL, D.G., BAZINET, M.L. and WEURMAN, C. 1962. Studies on volatile components of different varieties of cocoa beans. J. Food Sci. 27, 165-170.

COOK, I.R. and MEURSING, E.A. 1982. Chocolate Production and Use. Harcourt Brace Jovanovich, New York.

DIETRICH, P., LEDERER, E., WINTER, M. and STOLL, M. 1964. Recherches sur les aromes. Sur les aromas. Sur l'aroma de cacao. Helv. Chim. Acta 47, 1581-1590.

DIMICK, P.S. 1983. Development of flavour in chocolate. Proceedings Towards Better Acceptance of Malaysian Cocoa. Mardi, Serdang, Malaysia, 15-21.

DIMICK, P.S. and HOSKIN, J.M. 1981. Chemico-physical aspects of chocolate processing - a review. Can. Inst. J Food Sci. Tech. 4, 269-282.

FLAMENT, I., WILLHALM, B. and STOLL, M. 1967. Recherches sur les aromes. Sur l'arome du cacao III. Helv. Chim. Acta 50, 22332243.

GILL, M.S., MCLEOD, A.J. and MOREAU, M. 1984. Volatile compenents of cocoa with particular reference to glucosinolate product. Phytochemistry 23, 1937-1942.

HEINZLER, M. and EICHNER, K. 1992. The role of amodori compounds during cocoa processing - formation of aroma compounds under roasting conditions. Z. Lebensm.-Unters.-Forsch. 21, 445-450.

KEENEY, P.G. 1972. Various interaction in chocolate flavour. J. Am. Oil Chem. Soc. 49, 567-572.

KIM, H. and KEENEY, P.G. 1984. Epicatechin content in fermented and unfermented cocoa beans. J. Food Sci. 49, 1090-1092.

KRYSIAK, W., ICIEK, J. and MOTYL-PATELSKA, L. 2003. Influence of roasting conditions on selected physico-chemical properties of cocoa bean. Inżynieria Chemiczna i procesow 24, 509-523.

LEE, S.-Y., YOO, S.-S., Lee, M.-J., KWON, I.-B. and PYUN, Y.-R. 2001. Optimalization of nibs roasting in cocoa bean processing with Lotte-Better taste and color process. Food Sci. Biotechnol. 10, 286293.

MEMMERT, G., GROS, E. and GEORGES, G. 1982. Precursor consumption and cacao aroma development as a function of roasting. Café Cacao the 4, 285-289.

NAZARUDDIN, R., SURIAH, A.R., OSMAN, H., AYUB, M.Y., MAMOT, S., LIM, L.S. and NG, W.F. 2000. Caffein and theobromine levels in chocolate couverture and coating products. Mal. J. Nutr. 6, 55-63.

NAZARUDDIN, R., AYUB, M.Y., MAMOT, S. and HENG, C.H. 2001. HPLC determination of methylxanthines and polyphenols levels in cocoa and chocolate products. Mal. J. Anal. Sci. 7, 377-386. 
NEBESNY, E. and RUTKOWSKI, J. 1998. The effect of roasting and secondary fermentation on cocoa bean enrichment. Polish J. Of Food Nutrition and Science 3, 437-444.

Ö ZDEMIR, M. and DEVRES, Y.O. 2000. Analysis of color development during roasting of hazelnuts using response surface methodology. J. Food Eng. 45, 17-24.

REINECCIUS, G.A., KEENEY, P.G. and WEISSBERGER, W. 1972. Factors affecting the concentration of pyrazines in the cocoa beans. J. Agric. Food Chem. 20, 202-206.

RIZZI, G.P. 1967. The occurence of simple alkylpyrazines in cocoa butter. J. Agric. Food Chem. 15, 549-551.

ROHAN, T.A. and STEWART, T. 1965. Changes occuring in the constituents of Accra cocoa beans during roasting, volatile and nonvolatile acids. Rev. Int. Choc. 20, 522-523.

SAS. 1989. SAS User's Guide, Version 6.0. SAS Institute, Cary, NC.

VAN PRAAG, M., STEIN, H.S. and TIBBETS, M.S. 1968. Steam volatile aroma constituents of roasted cocoa beans. J. Agric. Food Chem. 16, $1005-1008$.

VITZTHUM, O.G., WERKHOFF, P. and HUBERT, P. 1975. Volatile compounds of roasted cocoa: Basic fraction. J. Food Sci. 40, 911-916.

ZIEGLEDER, G. 1982. Gas chromatographic determination of roasting degree for cocoa via methylated pyrazines. Dtsch. Lebensm.-Rundsch. $78,77-81$. 